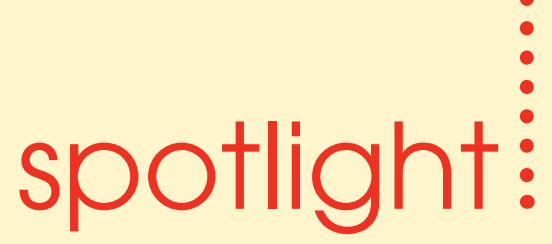

Going to the dentist Avril Webster; illustrated by David Ryley Speechmark $\mathfrak{E} 6.99$ ISBN: 9780863886317

Going to the dentist is a colourful paperback aimed at children aged 3-7 of all abilities, and is of particular benefit to those with intellectual disabilities or autism. It is one of six books in the Off we go! series, describing a simple everyday activity using simple text and colour illustrations (others include going to the doctor, hairdresser, supermarket, restaurant and swimming).

The series of books helps prepare children for unfamiliar activities so that they will feel less anxious and stressed, and so that they can hopefully enjoy the new experience. The author's own son, Stephen, has a moderate to severe intellectual disability which inspired Avril to create the books - and with the clear, uncluttered illustrations, she found them to be an effective way of communicating with him.
The books can be used at home before the event, and can also be taken along to use during each stage of the event itself. Each has 12 pages, a length recommended by

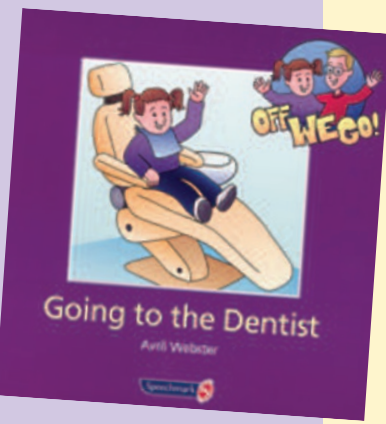

Stephen's speech \& language therapist.

Copies can be ordered at www.speechmark.net.

\title{
spotlight on dental hygienists and therapists
}

The following courses and events are ideal opportunities to network, keep up-to-date with new developments in the industry, improve your job prospects and top up CPD hours. Make sure you don't miss out! This list was supplied by the British Society of Dental Hygiene and Therapy (BSDHT). See www.bsdht.org.uk for everything you need to know about being a dental hygienist or dental therapist.

\section{Periodontal course - Exorcise your Dogmas (5 hours' CPD) 19 January 2008 \\ Presenters: Dr Graham Smart and Dr Phil Ower A challenging day of lectures and discussion on periodontal therapy that will attempt to sort out the evidence from the anecdote, drawing on the very latest published research, and may well change the way you manage your patients' periodontal problems. \\ Stoke Mandeville Hospital \\ For further details contact Karrie Archer on 01525376130.}

\section{BSDHT Southern Regional Group Spring Meeting}

3 March 2008

Details will become available at www.bsdht.org.uk.

\section{North East Regional Group Spring Meeting}

5 April 2008

Holiday Inn, Harrogate

For further details contact Julie Rosse on 01909561852.

\section{British Society of Periodontology (BSP) Spring Meeting}

13-15 April 2008

West Road Concert Hall, Cambridge

Including a conference dinner at the American Air

Museum, Duxford.

Topics will include periodontal therapy and research, tooth loss and decision making, smoking as an addiction, and depression and physical disease.

For further details see www. bsperio.org.uk.

\section{Spotlight - aultumn issue}

The spotlight on dental practice managers (Vital autumn 2007 page 14) listed out of date information about UMD Professional Ltd. The correct details are as follows:

UMD Professional Ltd. offers a range of courses and qualifications designed specifically for dental practice managers and business managers at a number of different levels. The courses are accredited by the Institute of Leadership and Management and lead to:

- the Level 3 Certificate in First Line Management

- the Level 5 Diploma in Management

- the Level 7 Executive Diploma in Management.

To accommodate people's individual circumstances, the Level 3 Certificate and the Level 5 Diploma are available both as distance learning programmes and as workshop-based courses. Distance learning courses can be started at any time, and workshop courses start at various dates throughout the year.

Both the distance learning and the workshop-based courses can be taken without the qualification element, and all courses provide verifiable CPD.

For a prospectus for any of these courses or for more information, please call Penny Parry on 02082552070 or email her on penny@umdprofessional.co.uk. 